\title{
Convergence and Divergence under Global Trade
}

\author{
David Mayer Foulkes ${ }^{1}$ \\ ${ }^{1}$ Centro de Investigación y Docencia Económicas, México D.F., México \\ Correspondence: David Mayer Foulkes, División de Economía, Centro de Investigación y Docencia Económicas, \\ Carretera México-Toluca 3655, 01210 México D.F., México. E-mail: david.mayer@cide.edu
}

Received: January 16, 2017

Accepted: February 8, 2017

Online Published: February 20, 2017

doi:10.5539/ijef.v9n3p194

URL: https://doi.org/10.5539/ijef.v9n3p194

\begin{abstract}
We construct a model of endogenous technological change with trade (in the absence of foreign direct investment separating innovation from production) that displays multiple steady states with divergence in levels and in growth rates. This shows trade can be a force for both development and underdevelopment. Our dynamic model of trade simultaneously explains: comparative advantage, the advantages of being open for the technological leader, that lagging countries might benefit from being closed, the possibility of divergence under trade for lagging countries, and under what circumstances lagging countries can converge to development under trade, possibly overtaking the leader. The sources of divergence we consider are inherent characteristics of the process of technological change (for example as described throughout Aghion and Howitt's work). The first is the need for absorptive capacity for innovators taking advantage of leading edge technologies. The second is the existence of innovation externalities between goods, the basis of technology spillovers and of the concept of "leading edge technology." It follows that the more goods are engaged in R\&D in any country, the more productive $\mathrm{R} \& \mathrm{D}$ is. We provide a historical discussion of the emergence of development and underdevelopment during the 19th Century and until 1914 that is consistent with and exemplifies the possibilities explained by the model.
\end{abstract}

Keywords: endogenous technological change, trade, convergence, divergence, underdevelopment

\section{Introduction}

While trade is widely held to be a force for convergence between countries, we argue that in fact trade can simultaneously be a force for development and for underdevelopment, and that this has been the case since the Industrial Revolution and the Great Divergence. To do so we provide a historical discussion of the First Great Age of Globalization during the 19th Century and until 1914, and a theoretical model of trade and economic growth that displays multiple steady states, representing development and underdevelopment, that can be applied both in the longer term or contemporaneously.

Two sources of divergence are considered, that are inherent characteristics of the process of technological change. The first is the need for absorptive capacity in taking advantage of leading edge technologies. The second is the existence of innovation externalities between goods, which implies that the more goods are engaged in R\&D in any country, the more productive $R \& D$ is. We explain below how these are essential characteristics that are implicit in the process of technological change as described by Aghion and Howitt through their work (e.g. Aghion \& Howitt, 1992, Aghion et al., 1998, Howitt, 2000, and so on).

Trade has played a major role in modern economic growth since its origins. It forms a major strand in Maddison's (2001) description of the economic ascension of Western Europe through Venice, Portugal, Spain, the Netherlands and Britain, from the year 1000 to the present. The Great Discoveries were motivated by the spice trade. Cotton exports in late 18th and early 19th Century England, widely recognized as the Industrial Revolution's leading sector, rose from $6 \%$ of total British exports in 1784-6 to a peak of $48.5 \%$ in $1834-6$ (Chapman, 1987). The growth of this sector and the incentives for its increased productivity were directly linked with imports of cheap raw materials from India at this initial juncture of the Great Divergence (Broadberry and Gupta, 2009). More recently, the rapid growth of Germany, Israel, Cyprus, Spain, Portugal, Malta, Ireland and Iceland were intimately linked with trade. More spectacularly, the development of Japan and the East Asian countries was also inextricably linked with trade.

Foreign direct investment (FDI) became a major actor towards the end of the 19th Century, with the Second 
Industrial Revolution. Wilkins (1970) identifies 1875-1914 as the period of “...the rise of truly large-scale foreign investments in the private sector" including "....more foreign direct investments than most subsequent commentaries have recognized" (cited in Lipsey, 2001). Investments in the colonial and dependent countries became a source of extraordinary profits, due to very cheap labor and raw materials. By 1899 giant corporations such as the United Fruit Company controlled 90 per cent of US banana imports. By 1914 Royal Dutch/Shell accounted for 20 per cent of Russia's total oil production and Standard Oil of New Jersey, Singer, International Harvester, Western Electric, and, Ford Motor Company had major production facilities outside the United States (Beaudreau, 2004). British assets abroad amounted to between 124 and 180\% of its GDP in 1914. Taking British investment as a whole, between 1865 and 1914 approximately as much went to underdeveloped Africa, Asia, and Latin America (29.6\%) as to the UK itself (31.8\%) (Ferguson, 2003). Svedberg (1978) estimates that some 44 to $60 \%$ of the $\$ 19$ billion of accumulated investment in developing countries in 1913-14 consisted of foreign direct investment.

Table 1. Examples of three types of growth patterns for open and closed economies

\begin{tabular}{|c|c|c|c|}
\hline & India and China & Mexico and Brazil & United States ${ }^{\dagger}$ \\
\hline \multirow{2}{*}{1820 Population } & India: 200M & Mexico: $6.5 \mathrm{M}$ & \multirow{2}{*}{$10 \mathrm{M}$} \\
\hline & China: $381 \mathrm{M}$ & Brazil: $4.5 \mathrm{M}$ & \\
\hline Institutions, governance & Weak, serving British interests & Weak, closed & Strong, inherited from Britain \\
\hline \multirow{3}{*}{ Trade } & Open by force: & & \multirow{3}{*}{$\begin{array}{c}\text { Discretionary: } \\
\text { “American System" based on industrial } \\
\text { protection }\end{array}$} \\
\hline & India: 1757 & High tariffs, many cities & \\
\hline & China: 1842 & & \\
\hline \multirow{2}{*}{1820 GDP per capita } & India: $\$ 533$ & Mexico: $\$ 759$ & \multirow{2}{*}{$\$ 1,257$} \\
\hline & China: $\$ 600$ & Brazil: $\$ 646$ & \\
\hline \multirow{2}{*}{1913 GDP per capita } & India: $\$ 673$ & Mexico: $\$ 1,732$ & \multirow{2}{*}{$\$ 5,301$} \\
\hline & China: $\$ 552$ & Brazil: $\$ 811$ & \\
\hline \multirow{2}{*}{$\begin{array}{l}\text { Growth factor } \\
1820-1913\end{array}$} & $\times 1.3$ & Mexico: $\times 2.3$ & \multirow{2}{*}{$\times 4.2$} \\
\hline & $\times 0.9$ & Brazil: $\times 1.3$ & \\
\hline \multirow{2}{*}{1980 GDP per capita ${ }^{\dagger}$} & India: $\$ 938$ & Mexico: $\$ 6,289$ & \multirow{2}{*}{$\$ 18,577$} \\
\hline & China: $\$ 1,067$ & Brazil: $\$ 5,198$ & \\
\hline \multirow{2}{*}{$\begin{array}{l}\text { Growth factor } \\
1820-1980\end{array}$} & $\times 1.8$ & Mexico: $\times 8.3$ & \multirow{2}{*}{$\times 14.8$} \\
\hline & $\times 1.8$ & Brazil: $\times 8.0$ & \\
\hline
\end{tabular}

Note. The table compares initial conditions in several peripheral countries in 1820, and economic growth from 1820 to 1913 and 1980.

†UK population in 1820: 21M. UK income: \$1,250 in 1700, \$1,706 in 1820, \$12,931 in 1980.

*1990 International Geary-Khamis dollars. Source: Maddison (2004).

Here we discuss and model the role of trade in economic growth and divergence. A closely related model for FDI is provided in Mayer-Foulkes (2015). (I consider the case when innovation occurs in one country and production in another to be FDI.) Thus here we are only concerned with innovation that occurs in the same countries that carry out production in each sector.

\subsection{Free Trade in the History of Development}

Notwithstanding Adam Smith's and David Ricardo's arguments for free trade, both Britain and the US adopted Free Trade only after they gained industrial supremacy. The repeal of the Corn Laws in Britain in 1846, allowing the import of grains, was based on the power of steam engine run industrial production to pay. Similarly, while US opposition to free trade had been a staple of 19th and early 20th century foreign policy, the metamorphosis to unwavering support for Free Trade occurred until 1934, when Roosevelt signed the Reciprocal Trade Agreements Act, based on electric power-based mass production supporting US industrial supremacy (Beaudreau, 2004).

To understand how industrial producers look at trade it is necessary to consider the dynamic impacts of trade on productivity. These reflect not only on the histories of developed countries, but also in the histories of weaker trading partners. Table 1 compares the initial conditions of lagging countries India, China, Mexico, Brazil, and the US in 1820, when Great Britain had become the industrial leader of its time. Both India and China were opened to trade by force, India in 1757 and China in 1842. From the point of view of sovereignty, their institutions were weak, and they were forced to follow policies serving British and other foreign interests. This 
was followed by a period of pronounced deindustrialization in India, China and the rest of the periphery (Williamson, 2004), as can be appreciated in Figure 1.

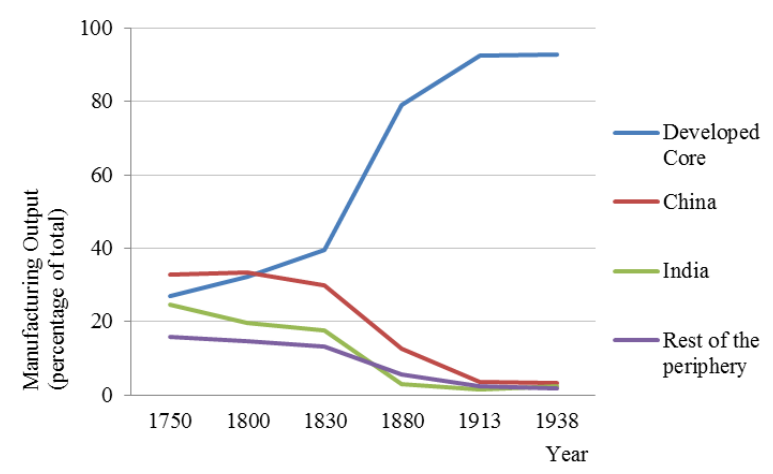

Figure 1. Distribution of manufacturing output by regions, 1750-1938

Note. Proportion of manufacturing output taking place in the Developed Core, China, India, and the rest of the periphery from 1750 to 1938. Source: Simmons (1985), quoted by Williamson (2004).

Mexico and Brazil, with much smaller populations, completed their independence in 1821 and 1823, with institutions inherited from Spain and Portugal. As in Latin America generally, the main cities were inland and governments used tariffs to finace themselves. Thus Mexico and Brazil were relatively closed to trade.

By 1820 the US was very well placed to imitate the British advances. Its first factory in 1790 was based on British textile machinery secrets brought by Samuel Slater to the US (Everett, 2006).

The American System was advanced by Henry Clay and others after 1812. It implemented high tariffs to protect American infant industries from British industrial supremacy, and promoted trade between North, South and West through transportation improvements. The South, having access to markets for its cotton, had no incentives to join the System, one of the causes of the Civil War (Spannaus et al., 2015; Salisbury, 2015).

Thus India and China were essentially open through the long 19th Century until 1914, while Mexico, Brazil and the US were relatively closed to trade during that time.

What is interesting here is that we see two quite different and persistent tiers of divergence. Between 1820 and 1980, India and China both multiplied their income per capita by 1.8. On the other hand, Mexico and Brazil multiplied their income per capita by 8.3 and 8.0. (Note that during this period India, China, Mexico, Brazil, and the US multiplied their populations by factors of 2.6, 3.2; 10.4, 27.3; and 22.8, the last two importantly through migration.) The US multiplied its income per capita by 14.8 , overtaking the industrial leader, Great Britain, which grew by a factor of 7.6 .

These figures are consistent with divergence in levels and divergence in growth rates, as well as the possibility of convergence and overtaking. Divergence in levels refers to trajectories, or steady states, with parallel growth, and divergence in growth rates to trajectories, or steady states, with different rates of growth, the higher one growing faster.

It is noteworthy that the lagging countries that were open to trade, India and China, diverged more than the countries closed to trade, Mexico and Brazil, and that a country capable of overtaking the leader, the US, chose to remain closed to do so.

A dynamic model of trade must therefore be able to simultaneously explain: comparative advantage and its benefits, the advantages of being open for the technological leader, why lagging countries might benefit from being closed, the possibility of divergence under trade for lagging countries, and under what circumstances lagging countries can converge to development under trade (such as the Asian tigers).

A further test of a dynamic trade model is to be able to explain the main features of the "Colonial Diktat" imposed by colonial powers on their colonies (See Bairoch, 1997), who asserts that the colonial diktat was the main cause for the non-transmission of the Industrial Revolution outside Europe).

The typical "colonial diktat" consisted of (a) colonies could import only products from the metropolis and tariff rates had to be low, normally $0 \%$; (b) colonial exports could be made only to the metropolis, from where they could be re-exported; (c) production of manufactured goods that could compete with metropolitan products was 
banned; and (d) transport between colony and metropolis was conducted only on metropolis ships. (See Beaudreau, 2004, who cites Bairoch, 1997).

To model the impact of trade on economic growth and divergence, first I extend the model in Howitt and Mayer-Foulkes (2005) to open, trading economies. The first source of divergence I consider is the need for an absorptive capacity for taking advantage of leading edge technologies. The second source of divergence that is modelled is innovation externalities between goods. Here the idea is that the more goods are engaged in R\&D in any country (the unit of analysis is really the knowledge system), the more productive $R \& D$ will be. More advanced and more populous countries will produce a wider variety of goods and will therefore have dynamic advantages in R\&D. This idea also applies to specialization in sets of goods where more innovation can take place, for example industrial production versus raw materials.

In what follows, we provide a model of trade and technological change that generates multiple steady states displaying divergence in levels and in growth rates. We then discuss its conclusions.

\section{The Model: Free Trade and Innovation}

We first describe production and trade and then turn to innovation

\subsection{Trade}

We introduce trade in the Howitt and Mayer-Foulkes (2005) model. Consider two countries, Country 1 and Country 2, that produce a set of tradeable goods indexed by $[0,1]$. We will assume that Country 1 is the technological leader. We use a continuum of tradeable goods that is analogous to the set of intermediate goods in Howitt and Mayer-Foulkes (2005). At time $t$, Country 1 produces on the set $\left[0, \xi_{l t}\right]$ and Country on the set $\left(\xi_{1 t}, 1\right]$, where

$$
\xi_{1 t}+\xi_{2 t}=1 .
$$

The sets $\left[0, \xi_{l t}\right],\left[\xi_{l t}, 1\right]$ of goods which each country produces are assigned by trade through international competition by prices. This involves both the technological level and a comparative advantage in the production of each good.

To simplify the model we assume that for each good produced by a country, there is a single infinitely lived incumbent who innovates with certainty. For each good the incumbent produces as a monopolist, subject to a competitive fringe producing with a smaller productivity by a factor of $x>1$. Therefore the incumbent can sell at a price which is a multiple $x$ of her cost. For simplicity we assume this factor is the same in both countries. Since innovation proceeds with certainty, we assume that all goods in each country share the same technological level.

To express some of the economic quantities symmetrically between countries, we let $\xi_{2}=1-\xi_{1}$ and consider variables $\eta_{1} \in\left[0, \xi_{1 t}\right]=G_{1 t}, \quad \eta_{2} \in\left[0, \xi_{2 t}\right)=G_{2 t}$ indexing the goods each country produces. When instead we use an index $\eta \in[0,1]$ for the whole interval of goods, when $\eta \in\left[0, \xi_{1 t}\right]$ it represents a good produced by Country 1 , while when $\eta \in\left(\xi_{1 t}, 1\right]$, it represents through a change of variable good $\eta_{2}=1-\eta \in\left[0, \xi_{2 t}\right)$ produced by Country 2 .

The production functions for good $\eta_{i} \in G_{i t}$ produced by Country $i$, with $i=1,2$, are

$$
y_{i t}\left(\eta_{i}\right)=\left(1-\kappa \eta_{i}\right) A_{i t} l_{i t}\left(\eta_{i}\right), \quad i=1,2 .
$$

All goods produced by Country $i$ share the same technological level $A_{i t}$ at any time $t$. They employ $l_{i t}\left(\eta_{i}\right)$ units of labor at time $t$ in good $\eta_{i}$. Finally, each good $\eta_{i}$ has a fixed productivity effect $1-\kappa \eta_{i}$, where $0 \leq \kappa \leq 1$. This means that goods are ordered in a gradient of comparative advantage that goes in opposite directions for each country. The parameter $\kappa$ is introduced to be able to compare degrees of comparative advantage. The case $\kappa=0$ means there is no comparative advantage, while the case $\kappa=1$ is the maximum (in this representation) for which productivity is positive under autarchy for all goods (except for a single good ). The technological level will also have an impact on competitive advantage and the equilibrium under trade. Relative wages between countries will adjust in equilibrium so that each country employs its labor in goods more cost effectively than if the other country attempted their production. We assume there are no transportation costs.

The cost of production of each good $\eta_{i}$ in country $i$ at time $t$ is therefore: 


$$
\varphi_{i t}\left(\eta_{i}\right)=\frac{w_{i t}}{\left(1-\kappa \eta_{i}\right) A_{i t}}, \quad i=1,2
$$

Where $w_{i t}$ is the wage paid for labor in each country. Since the incumbent sells at a multiple $x$ of the cost, the price is,

$$
p_{i t}\left(\eta_{i}\right)=\frac{\chi w_{i t}}{\left(1-\kappa \eta_{i}\right) A_{i t}}, \quad i=1,2
$$

Let the instantaneous consumer utility $U=U\left(C_{t}\right)$ depend on a subutility function $C_{t}$ for an agent consuming $c_{t}(\eta)$ units of good $\eta$ goods, $\eta \in[0,1]$, according to the Cobb-Douglass function

$$
\ln \left(C_{t}\right)=\int_{0}^{1} \ln \left(c_{t}(\eta)\right) d \eta
$$

This preference function takes the place of the final good production function in Howitt and Mayer-Foulkes (2005). We use this Cobb-Douglass function for 1) consumption preferences and also for 2) the composite good $X_{t}$ used for research inputs, defined as

$$
\ln \left(X_{t}\right)=\int_{0}^{1} \ln \left(x_{t}(\eta)\right) d \eta .
$$

Hence world expenditure across goods will be constant for both consumption and innovation. Since at each time $t$ expenditure $z_{t}$ is constant across goods,

$$
p_{i t}\left(\eta_{i}\right) y_{i t}\left(\eta_{i}\right)=\frac{\chi w_{i t}}{\left(1-\kappa \eta_{i}\right) A_{i t}}\left(1-\kappa \eta_{i}\right) A_{i t} l_{i t}\left(\eta_{i}\right)=\chi w_{i t} l_{i t}\left(\eta_{i}\right)=z_{t},
$$

It follows in this stylized model also $l_{i t}\left(\eta_{i}\right)=l_{i t}$ is independent of $\eta_{i}$. In each country $i$ at each time $t$ an equal number $l_{i t}$ of workers produces each good. Profits in each good are:

$$
\pi_{i t}=\left(1-\chi^{-1}\right) z_{t} \text {. }
$$

Let $L_{1}, L_{2}$ be the number of workers in each country, which we assume constant for simplicity. In Country $i$, $l_{i t}$ workers work on a measure $\xi_{i t}$ of goods, so $\xi_{i t} l_{i_{t}}=L_{i}$, and therefore

$$
l_{i t}=L_{i} / \xi_{i t}, \quad i=1,2 \text {. }
$$

Observe by equation (4) that prices $p_{i t}\left(\eta_{i}\right)$ are increasing in $\eta_{i}$. For this reason the goods that each country will cease to produce first correspond to higher values of $\eta_{i}$. For low productivity countries, wages decrease to the point were employment takes place on some interval of goods. Under free trade the boundary of this interval is defined by some unique good $\eta_{1}=\xi_{1 t}$ for which both countries produce at the same price. The corresponding good in symmetric notation is $\eta_{2}=\xi_{2 t}=1-\xi_{1 t}$ in Country 2. Hence the trade equilibrium occurs when

$$
p_{1 t}\left(\xi_{1 t}\right)=p_{2 t}\left(1-\xi_{1 t}\right) \Leftrightarrow \frac{\chi w_{1 t}}{\left(1-\kappa \xi_{1 t}\right) A_{1 t}}=\frac{\chi w_{2 t}}{\left(1-\kappa\left(1-\xi_{1 t}\right)\right) A_{2 t}} .
$$

Country 1 produces on the set $\left[0, \xi_{1 t}\right]$ and Country 2 on the set $\left(\xi_{1 t}, 1\right]$. (I have simply assumed that sector $\xi_{1 t}$, as a point a set of measure 0 , is produced by Country 1.) Since expenditure is independent of $\eta_{i}$ across goods, and payrolls are a fixed proportion $\chi^{-1}$ of sales income, it follows $w_{1 t} l_{1 t}=w_{2 t} l_{2 t}$. Multiplying each side of the second equation in (10) by $l_{i} / l_{i}$ and using (9), we obtain

$$
\frac{1-\kappa \xi_{1 t}}{\xi_{1 t}} L_{1} A_{1 t}=\frac{1-\kappa\left(1-\xi_{1 t}\right)}{1-\xi_{1 t}} L_{2} A_{2 t}
$$

Definition 1. Let the relative technological and population levels between the two countries, and the ratio of their effective labor levels, be

$$
a_{t}=\frac{A_{2 t}}{A_{1 t}}, \quad \lambda=\frac{L_{2}}{L_{1}}, \quad b_{t}=a_{t} \lambda .
$$

We assume Country 1 is the technological leader so $a_{t} \leq 1$.

Proposition 2. Under trade, the sectors of production are assigned as a fucntion of $b_{t}$, the relative size of the economies. There exist functions 


$$
\xi_{1 t}=\xi_{1}\left(b_{t}\right) \in(0,1), \quad \xi_{2 t}=1-\xi_{1}\left(b_{t}\right),
$$

that define the intervals on which each country produces and satisfy

$$
\xi_{1}(0)=1, \quad \xi_{1}(1)=\frac{1}{2}, \quad \lim _{b_{t} \rightarrow \infty} \xi_{1}\left(b_{t}\right)=0, \quad \xi_{1}^{\prime}\left(b_{t}\right)<0 .
$$

Proof. (11) implies

$$
\frac{\left(1-\kappa \xi_{1 t}\right) \xi_{2 t}}{\xi_{1 t}\left(1-\kappa \xi_{2 t}\right)}=\frac{\left(1-\kappa \xi_{1 t}\right)\left(1-\xi_{1 t}\right)}{\xi_{1 t}\left(1-\kappa\left(1-\xi_{1 t}\right)\right)}=b_{t} .
$$

This function on the left hand side (LHS) decreases from infinity to zero on the interval $\xi_{1 t} \in(0,1]$, and has non zero derivative. Hence a unique differentiable inverse function exists as in (13), with properties (14). Note that $\xi_{1}\left(b_{t}\right)$ solves a quadratic equation.

Note that the smaller the relative economic size of Country 2, as measured by $A_{2 t} L_{2} / A_{1 t} L_{1}$, the smaller the number of goods it produces in.

Theorem 3. For any given technological levels $A_{l t}, A_{2 t}$ production, wages and profits are higher under trade than under autarchy. Wages and incomes $Y_{l t}, Y_{2}$, of each country, and total income $Y_{t}$ are:

$$
\begin{gathered}
w_{1 t}=\frac{A_{1 t}}{e \chi\left(1-\kappa \xi_{1 t}\right)^{\frac{1}{\kappa}-1}\left(1-\kappa \xi_{2 t}\right)^{\frac{1}{\kappa}}}, \quad w_{2 t}=\frac{A_{2 t}}{e \chi\left(1-\kappa \xi_{1 t}\right)^{\frac{1}{\kappa}}\left(1-\kappa \xi_{2 t}\right)^{\frac{1}{\kappa}-1}} . \\
Y_{1 t}=\frac{\left(1-\kappa \xi_{1 t}\right) A_{1 t} L_{1}}{e\left(1-\kappa \xi_{1 t}\right)^{\frac{1}{\kappa}}\left(1-\kappa \xi_{2 t}\right)^{\frac{1}{\kappa}}}, \quad Y_{2 t}=\frac{\left(1-\kappa \xi_{2 t}\right) A_{1 t} L_{1}}{e\left(1-\kappa \xi_{1 t}\right)^{\frac{1}{\kappa}}\left(1-\kappa \xi_{2 t}\right)^{\frac{1}{\kappa}}}, \\
Y_{t}=\frac{\left(1-\kappa \xi_{1 t}\right) A_{1 t} L_{1}+\left(1-\kappa \xi_{2 t}\right) A_{2 t} L_{2}}{e\left(1-\kappa \xi_{1 t}\right)^{\frac{1}{\kappa}}\left(1-\kappa \xi_{2 t}\right)^{\frac{1}{\kappa}}} .
\end{gathered}
$$

Prices can be expressed

$$
p_{t}(\eta)= \begin{cases}\frac{\frac{1-\kappa \xi_{1 t}}{1-\kappa \eta}}{e\left(1-\kappa \xi_{1 t}\right)^{\frac{1}{\kappa}}\left(1-\kappa \xi_{2 t}\right)^{\frac{1}{\kappa}}} & \eta \in\left[0, \xi_{1 t}\right], \\ \frac{1-\kappa \xi_{2 t}}{1-\kappa(1-\eta)} & \eta \in\left(\xi_{1 t}, 1\right] . \\ \frac{1\left(1-\kappa \xi_{1 t}\right)^{\frac{1}{\kappa}}\left(1-\kappa \xi_{2 t}\right)^{\frac{1}{\kappa}}}{} & \end{cases}
$$

Proof. Equation (10) now implies the wage ratio is,

$$
\frac{w_{2 t}}{w_{1 t}}=\frac{1-\kappa \xi_{2 t}}{1-\kappa \xi_{1 t}} a_{t}=\frac{\xi_{2 t}}{\lambda \xi_{1 t}} .
$$

since using (15),

$$
\frac{1-\kappa \xi_{2 t}}{1-\kappa \xi_{1 t}} b_{t}=\frac{\xi_{2 t}}{\xi_{1 t}}
$$

The total production of each good is:

$$
y_{i t}\left(\eta_{i}\right)=\left(1-\kappa \eta_{i}\right) A_{i t} l_{i t}\left(\eta_{i}\right), \quad i=1,2 .
$$

We now calculate the aggregate products of each country. We use the following notation for functions considered for both countries simultaneously.

$$
y_{t}(\eta)=\left\{\begin{array}{cc}
y_{1 t}(\eta) & \eta \in\left[0, \xi_{1 t}\right], \\
y_{2 t}(1-\eta) & \eta \in\left(\xi_{1 t}, 1\right],
\end{array}\right.
$$


and similarly for other variables such as $p_{i t}\left(\eta_{i}\right)$ :

$$
p_{t}(\eta)= \begin{cases}\frac{\chi w_{1 t}}{(1-\kappa \eta) A_{1 t}} & \eta \in\left[0, \xi_{1 t}\right], \\ \frac{\chi w_{2 t}}{(1-\kappa(1-\eta)) A_{2 t}} & \eta \in\left(\xi_{1 t}, 1\right] .\end{cases}
$$

Given these prices, let $Y_{t}$ be the amount of composite good that can be produced using all of the goods produced. The part of the integral (6) involving goods from Country 1 is

$$
\begin{aligned}
\int_{0}^{\xi_{1} t} \ln \left(y_{t}(\eta)\right) d \eta=\int_{0}^{\xi_{1 t}} \ln ( & \left.(1-\kappa \eta) A_{1 t} l_{1 t}(\eta)\right) d \eta \\
& =\int_{0}^{\xi_{1 t}} \ln (1-\kappa \eta) d \eta+\xi_{1 t} \ln \left(A_{1 t} \frac{L_{1}}{\xi_{1 t}}\right) \\
& =\left[-\frac{1}{\kappa}(1-\kappa \eta) \ln (1-\kappa \eta)-\eta\right]_{0}^{\xi_{1 t}}+\ln \left(\left(A_{1 t} \frac{L_{1}}{\xi_{1 t}}\right)^{\xi_{1 t}}\right) \\
& =-\frac{1}{\kappa}\left(1-\kappa \xi_{1 t}\right) \ln \left(1-\kappa \xi_{1 t}\right)-\xi_{1 t}+\ln \left(\left(A_{1 t} \frac{L_{1}}{\xi_{1 t}}\right)^{\xi_{1 t}}\right) \\
& =\ln \left(\left(1-\kappa \xi_{1 t}\right)^{-\frac{1-\kappa \xi_{1 t}}{\kappa}}\left(\frac{A_{1 t} L_{1}}{e \xi_{1 t}}\right)^{\xi_{1 t}}\right)
\end{aligned}
$$

Adding to this the component from Country 2,

$$
Y_{t}=\frac{\left(A_{1 t} L_{1}\right)^{\xi_{1 t}}\left(A_{2 t} L_{2}\right)^{\xi_{2 t}}}{e\left(1-\kappa \xi_{1 t}\right)^{\frac{1-\kappa \xi_{1 t}}{\kappa}}\left(1-\kappa \xi_{2 t}\right)^{\frac{1-\kappa \xi_{2 t}}{\kappa}} \xi_{1 t}^{\xi_{1 t}} \xi_{2 t}^{\xi_{2 t}}} .
$$

The income of the inputs of the composite accruing to Country 1 is $\chi W_{1 t} L_{1}$. Hence, taking the price of the composite as numeraire,

$$
1=\frac{\chi w_{1 t} L_{1}+\chi w_{2 t} L_{2}}{Y_{t}}=\frac{\chi w_{1 t} L_{1}\left(1+\frac{\xi_{2 t}}{\xi_{1 t}}\right) e\left(1-\kappa \xi_{1 t}\right)^{\frac{1-\kappa \xi_{1 t}}{\kappa}}\left(1-\kappa \xi_{2 t}\right)^{\frac{1-\kappa \xi_{2 t}}{\kappa}} \xi_{1 t}^{\xi_{1 t}} \xi_{2 t}^{\xi_{2 t}}}{\left(A_{1 t} L_{1}\right)^{\xi_{1 t}}\left(A_{2 t} L_{2}\right)^{\xi_{2 t}}}
$$

where we have used (20), so

$$
w_{1 t}=\frac{A_{1 t}}{\chi} \frac{\xi_{1 t} b_{t}^{\xi_{2 t}}}{e\left(1-\kappa \xi_{1 t}\right)^{\frac{1}{\kappa}-\xi_{1 t}}\left(1-\kappa \xi_{2 t}\right)^{\frac{1}{\kappa}-\xi_{2 t}} \xi_{1 t}^{\xi_{1 t}} \xi_{2 t}^{\xi_{2 t}}} .
$$

Note that it follows from (26) that the total expenditure in all goods is $Y_{t}$. Hence this is aso the total expenditure in each good, since the total measure for all goods is 1 . Because the intermediate consumption utility $C_{t}$ and the composite good $X_{t}$ used for innovation are defined using the same homogeneous Cobb Douglass function of degree 1, the proportions $c_{t}(\eta), x_{t}(\eta)$ of total production $y_{t}(\eta)$ of each good used for consumption, or for innovation, do not differ between goods, and we will have $C_{t}+X_{t}=e_{t}=Y_{t}$.

Equations (15) imply

$$
\begin{gathered}
\frac{\left(1-\kappa \xi_{1 t}\right) \xi_{2 t}}{\xi_{1 t}\left(1-\kappa \xi_{2 t}\right)}=b_{t} \Rightarrow \frac{\left(1-\kappa \xi_{1 t}\right)^{\xi_{2 t}} \xi_{2 t}^{\xi_{2 t}}}{\xi_{1 t}^{\xi_{2 t}}\left(1-\kappa \xi_{2 t}\right)^{\xi_{2 t}}}=b_{t}^{\xi_{2 t}} \\
\Rightarrow \frac{\left(1-\kappa \xi_{1 t}\right) \xi_{1 t}^{\xi_{1 t}} \xi_{2 t}^{\xi_{2 t}}}{\left(1-\kappa \xi_{1 t}\right)^{\xi_{1 t}}\left(1-\kappa \xi_{2 t}\right)^{\xi_{2 t}}}=\xi_{1 t} b_{t}^{\xi_{2 t}}
\end{gathered}
$$


Hence expression (27) simplifies to (16), the expression for $w_{2 t}$ being obtained similarly. Using the first equality in (26), the total income $Y_{i}=\chi w_{i t} L_{i}$, of each country can be written as in (17), and the total income (18). Expressions (16), (17), (18) show wages and production rise under trade. This can be seen as follows. For Country 1 , under autarchy $\xi_{1 t}=1, \xi_{2 t}=0$. Hence

$$
Y_{1 t}^{\text {autarchy }}=\frac{A_{1 t} L_{1}}{e(1-\kappa)^{\frac{1}{\kappa}-1}} .
$$

Hence

$$
\frac{Y_{1 t}^{\text {autarchy }}}{Y_{1 t}}=\frac{\left(1-\kappa \xi_{1 t}\right)^{\frac{1}{\kappa}-1}\left(1-\kappa \xi_{2 t}\right)^{\frac{1}{\kappa}}}{(1-\kappa)^{\frac{1}{\kappa}-1}}<1
$$

since $(1-\kappa \xi)^{\frac{1}{\kappa}-1}$ is a decreasing function in $\xi$. Finally, using expressions (16), for real wages, prices (24) can be expressed as in (19).

Wages are higher in countries with higher technology. Also they are higher in countries with less goods in production, because more of their production will take place in goods with a higher comparative advantage. Hence they are higher for countries with a smaller population.

Our setup reproduces the standard results, from the static point of view. Taking technological levels as given, each economy has higher income and wages under trade than under autarchy. However, an additional result appears. The number of sectors under production in each country is proportional to the size of the economy, which itself is proportional to the population and technological levels. This means that larger and more advanced countries will produce in more sectors than smaller and laggin countries. This can have an impact on technological change, and therefore on the long-term benefits of trade. We turn to these issues now.

\subsection{Technological Change}

Throughout their work, Aghion and Howitt describe the process of technological change as follows:

1) Resources are used for innovating a new production technology for some good. If this research effort is successful, a higher level of technology will result for producing this good. Research is conducted taking into account new technologies that are becoming available. Successful research is often modelled as implementing new, leading technologies.

2) The leading edge technology is a measure of the externalities or spillovers that results from all of new technologies that research in the economy makes available. Often a separate variable represents this as an aggregate, "the leading edge technology."

Now, the resources used for raising the technological level can consist of knowledge or goods. Absent credit, the resources available on average in different countries are proportional to their level of production and knowledge, both of which are closely related to their technological level (e.g Howitt \& Mayer-Foulkes, 2005). If credit is imperfect, available resources for innovation are also proportional to income and therefore to the technological level (e.g. Aghion, Howitt, \& Mayer-Foulkes, 2005). We can think of these combined resources available for innovation as the absorptive capacity. In single country models, for which the reference technological level of the economy is constant, the implicit absorptive capacity is often ignored. However, in multiple country models the idea that absorptive capacity intervenes in technological change and is proportional to the technological level is natural and follows from the inherent structure of the innovation process. Divergence can follow from this, and thus follows inherently from the properties of innovation, without any other assumption about what can make a countries backward.

Turning to the leading edge technology, this is really an aggregate construct for research spillovers or externalities (or technological transfer) available from all of the research taking place in the economy. That is, it represents positive innovation externalities across goods. In Howitt (2000) the leading edge technology is defined as the maximum technological level in all countries and sectors. In fact, though, real-world aggregation of these spillovers is much more complex. For example, spillovers have greater and more immediate impacts within than between countries, especially between developed and underdevelopled countries, which are more distant in several ways. In effect the "leading edge technology" is in constant formation, as an aggregation of 
technological spillovers transmitted across different channels. (See Coe \& Helpman, 1995 for a study of international R\&D spillovers.)

Below we consider a leading edge technology defined as the positive innovation externalities of goods whose innovation takes place in the same country. This is a reference case representing spillovers that are more easily transmitted between researchers in the same country and at the same technological level. This component of the leading edge technology externality can be a force leading to divergence.

We turn to the innovation model. As mentioned above, for each good there is a single, infinitely lived innovator who can produce an innovation for the next period. For simplicity, we are therefore abstracting from creative destruction. In effect this implies that we are considering creative destruction that is neutral to trade, and that the innovation effectiveness and cost parameters are net of creative destruction.

We consider a continuous model in which innovations are incremental, or smooth. Observe that good $\eta$ will only be in production in one country, either 1 or 2 , because under the equilibrium wages it will have a slight comparative advantage in this country. Hence it also has a slight advantage for production after innovation, and therefore innovation in good $\eta$ will only occur in the country that produces it. We also assume that when the boundary $\xi_{l t}$ shifts so that some goods start being produced in the other country, the incumbent from that country immediately takes over production and innovation at the country's own technological level.

I use a continuous model because it is ammenable to two variables. Here only one variable is used. This leaves scope for other applications.

Definition 4. An agent has perfect myopic expectations if she can predict economic variables over a horizon $\Delta t$ when this horizon tends to zero.

In this case we will consider an innovator with perfect myopic expectations who maximizes profits in the short term $\Delta t$ by choosing innovation inputs, and then let $\Delta t \rightarrow 0$ to establish her decision at any time $t$. This eliminates the need for considering the second set of variables that is needed for infinite foresight. In fact a discrete model with two periods also has a similar type of shortsighted foresight. Mayer-Foulkes (2015) shows that this definition of myopic foresight is equivalent to defining perfect myopic foresight as having perfect knowledge of the current economic variables' time derivatives.

In describing innovation, I first consider the role of technological absorptive capacity. Then I consider positive innovation externalities across goods when innovation takes place in the same country (or knowledge system). Both of these will be sources of divergence.

The effectiveness of innovation investment entrepreneur producing good $\eta$ will have three components. The first is knowledge and is proportional to the skill level $S_{j t}=A_{j t}$ that she has been able to accumulate in production, which we assume is the technological level of her firm. This generates a disadvantage of backwardness. The second component considers the impact of nascent, positive externalities from other firms' technological edge, $(1+\sigma) A_{1 t}$. This term represents externalities from research for other goods, presenting itself in diverse forms as nascent possibilities, either in the form of ideas or embodied in the use of other firm's goods at time $t+\Delta t$. It is represents the formation of a leading technological edge through innovation externalities, as in Howitt and Mayer-Foulkes (2005), which we eliminate, simplifying the model by one variable. The difference $\left((1+\sigma) A_{1 t}-A_{j t}\right) \Delta t$ measures how far back our innovating firm is from these nascent possibilities, contributing an advantage of backwardness that generates convergence. The effectiveness of these combined inputs is inversely proportional to the level of the nascent possibilities, the fishing out effect. The third component is a material input $v \Delta t$. Innovation occurs with certainty combining these components to obtain a technological level $A_{t+\Delta t}$ according to:

$$
A_{t+\Delta t}=A_{j t}+\mu_{j}\left(\frac{\left((1+\sigma) A_{1 t}-A_{j t}\right) S_{j t} \Delta t}{(1+\sigma) A_{1 t}}\right)^{\beta}(v \Delta t)^{1-\beta}, \quad j \in\{1,2, F D I\} .
$$

This means that the impact of an innovator on the technological change that a firm can obtain is proportional to her skill level, proportional to its distance to the nascent technological frontier, and inversely proportional to the nascent technological frontier. In addition, these knowledge impacts combine with material inputs according to a Cobb-Douglass function. 
The parameter $\mu_{j}$ represents the innovation productivity of the combined inputs. Innovation externalities will be introduced below by modifying this parameter.

Using myopic perfect foresight, so as $\Delta t \rightarrow 0$ any firm correctly expects the new technological levels $A_{j t+\Delta t}$, the profits level of an individual firm innovating to a technological level $A_{t+\Delta t}$ is:

$$
\pi_{t+\Delta t}=\left(1-\left(\frac{A_{j t+\Delta t}}{\chi A_{t+\Delta t}}\right)^{1-\alpha}\right) Y_{t+\Delta t},
$$

since as we saw, the total expenditure in each good is $Y_{t}$, where $A_{j t+\Delta t} A_{t+\Delta t}$ measures the comparative reduction in costs. Hence the profit maximizing rate of innovation investment is obtained by maximizing:

$$
\max _{v} e^{-\delta \Delta t}\left(1-\left(\frac{A_{j t+\Delta t}}{\chi A_{t+\Delta t}(v)}\right)^{1-\alpha}\right) Y_{t+\Delta t}-\left(1-\phi_{j}\right) v \Delta t
$$

where $e^{-\delta \Delta t}$ is the discount factor, and $\Phi_{j} \in(0,1)$ represents an innovation subsidy, a (positive or negative) proxy for all distortions and policies affecting the incentives to innovate.

Theorem 5. The rates of technological change of the leading and lagging countries are given by:

$$
\frac{\dot{A}_{1 t}}{A_{1 t}}=\frac{\sigma}{1+\sigma} \tilde{\mu}_{1} \Upsilon\left(a_{t}\right)^{\frac{1-\beta}{\beta}}, \quad \frac{\dot{A}_{2 t}}{A_{2 t}}=\tilde{\mu}_{2}\left(1-\frac{a_{t}}{1+\sigma}\right) \Upsilon\left(a_{t}\right)^{\frac{1-\beta}{\beta}} .
$$

The rates of change of their relative technological level is:

$$
\frac{\dot{a}_{t}}{a_{t}}=\left(\left(1-\frac{a_{t}}{1+\sigma}\right) \tilde{\mu}_{2}-\frac{\sigma}{1+\sigma} \tilde{\mu}_{1}\right) \Upsilon\left(a_{t}\right)^{\frac{1-\beta}{\beta}} .
$$

Here

$$
\begin{gathered}
\tilde{\mu}_{j}=\left(\frac{(1-\alpha)(1-\beta)}{\chi^{1-\alpha}\left(1-\phi_{j}\right)}\right)^{\frac{1-\beta}{\beta}} \mu_{j}^{\frac{1}{\beta}}, \\
\Upsilon\left(a_{t}\right)=\frac{Y_{t}}{A_{1 t}}=\frac{\left(1-\kappa \xi_{1 t}\right) L_{1}+\left(1-\kappa \xi_{2 t}\right) a_{t} L_{2}}{e\left(1-\kappa \xi_{1 t}\right)^{\frac{1}{\kappa}}\left(1-\kappa \xi_{2 t}\right)^{\frac{1}{\kappa}}} .
\end{gathered}
$$

Proof. Writing $A_{t+\Delta t}=A_{j t+\Delta t}$, since firms in sector $j$ are symmetric ex-post, the first order condition is:

$$
\frac{e^{-\delta \Delta t}(1-\alpha) b_{j t}\left(\chi^{-1} A_{j t+\Delta t}\right)^{1-\alpha}}{A_{j t+\Delta t}^{2-\alpha}}(1-\beta) \mu_{j} \times\left(\frac{\left((1+\sigma) A_{1 t}-A_{j t}\right) S_{j t} \Delta t}{(1+\sigma) A_{1 t}}\right)^{\beta}(v \Delta t)^{-\beta} Y_{t+\Delta t} \Delta t=\left(1-\phi_{j}\right) \Delta t .
$$

Letting $\bar{\mu}_{j}=\frac{(1-\alpha)(1-\beta)}{\chi^{1-\alpha}\left(1-\phi_{j}\right)} \mu_{j}$, material inputs $v$ are given by:

$$
(v \Delta t)^{\beta}=e^{-\delta \Delta t} b_{j t} \bar{\mu}_{j}\left(\frac{\left((1+\sigma) A_{1 t}-A_{j t}\right) S_{j t} \Delta t}{(1+\sigma) A_{1 t}}\right)^{\beta} \frac{Y_{t+\Delta t}}{A_{1 t+\Delta t}},
$$

Domestic innovators decide

$$
A_{t+\Delta t}=A_{j t}+\mu_{j}\left(\frac{\left((1+\sigma) A_{1 t}-A_{j t}\right) S_{j t} \Delta t}{(1+\sigma) A_{1 t}}\right)\left(e^{-\delta \Delta t} \bar{\mu}_{j} \frac{Y_{t+\Delta t}}{A_{1 t+\Delta t}}\right)^{\frac{1-\beta}{\beta}}, \quad j \in\{1,2\} .
$$

Note also that since $y_{t+\Delta t}$ depends on $a_{t}$ a relative scale effects is introduced that complicates the dynamics. This aspect is simplified by using continuous myopic foresight. Now set: $\tilde{\mu}_{j}=\mu_{j} \bar{\mu}_{j}^{(1-\beta) / \beta}$, which is equivalent to (32), noting that this final innovativity parameter for each economy is decreasing in market power $x$, because, as can be seen by following the derivative above, the higher the market power, the relatively lower the input costs and therefore the lower the impact of technological improvement on profit. Taking the limit as $\Delta t \rightarrow 0$, and writing 
$A_{t+\Delta t}=A_{j t+\Delta t}$,

$$
\dot{A}_{j t}=\tilde{\mu}_{j} \frac{(1+\sigma) A_{1 t}-A_{j t}}{(1+\sigma) A_{1 t}} A_{j t} L_{1} \Upsilon\left(a_{t}\right)^{\frac{1-\beta}{\beta}}, \quad j \in\{1,2\} .
$$

where, using (18), (33) is obtained. The case $j=1$ yields the rate of growth of technology in Economy 1 . This gives a scale effect in $L_{l}$ for the global growth rate that depends on the size of the global economy relative to $A_{l t}$. The case $j=2$ yields the rate of growth of technology in Economy 2. The difference yields the rate of growth of the relative technological level $a_{t}$.

We can now describe the technological dynamics in the ordinary case when an absorption capacity is needed for technological change.

Theorem 6. Country 1 's technological level $A_{1 t}$ grows at a rate $g\left(a_{t}\right)=\frac{\sigma}{1+\sigma} \tilde{\mu}_{1} \Upsilon\left(a_{t}\right)^{\frac{1-\beta}{\beta}}$ that is increasing in the size of the global economy, and higher than under autarchy. If Country 2 's innovativity

a) satisfies $\tilde{\mu}_{2}<\frac{\sigma}{1+\sigma} \tilde{\mu}_{1}$, Country 2 diverges in growth rates with Country 1 ;

b) satisfies $\tilde{\mu}_{2} \in\left[\frac{\sigma}{1+\sigma} \tilde{\mu}_{1}, \tilde{\mu}_{1}\right]$, Country 2 diverges in levels with Country 1 and converges to a steady state $a^{*}=1+\sigma-\sigma \frac{\tilde{\mu}_{1}}{\widetilde{\mu}_{2}}$

c) satisfies $\tilde{\mu}_{2}>\tilde{\mu}_{1}$., Country 2 overtakes Country 1

Proof. For the first statement, note $\Upsilon\left(a_{t}\right)=\frac{Y_{t}}{A_{t t}}>\frac{Y_{t t}}{A_{t t}}>\frac{Y_{t t}^{\text {autarchy }}}{A_{t t}}$. For the performance of Country 2, note that $\left(1-\frac{a_{t}}{1+\sigma}\right) \tilde{\mu}_{2}-\frac{\sigma}{1+\sigma} \tilde{\mu}_{1}$ is decreasing in $a_{t}$ and equal to $\frac{\sigma}{1+\sigma}\left(\tilde{\mu}_{2}-\tilde{\mu}_{1}\right)$ at $a_{t}=1$. Thus Country 2 overtakes Country 1 if $\tilde{\mu}_{2}>\tilde{\mu}_{1}$. On the other hand the same expression is negative at $a_{t}=0$ if $\tilde{\mu}_{2}<\frac{\sigma}{1+\sigma} \tilde{\mu}_{1}$. Hence under this condition Country 2 diverges in growth rates with Country 1 , with

$$
\lim _{t \rightarrow \infty} \frac{\dot{A}_{2 t}}{A_{2 t}}=\tilde{\mu}_{2} \Upsilon(0)^{\frac{1-\beta}{\beta}}<\lim _{t \rightarrow \infty} \frac{\dot{A}_{1 t}}{A_{1 t}}=\frac{\sigma}{1+\sigma} \tilde{\mu}_{1} \Upsilon(0)^{\frac{1-\beta}{\beta}} .
$$

In the intermediate cases Country 2 diverges in levels with Country 1 , to the given steady state.

\subsection{Innovation Externalities}

Recall that more advanced and more populous countries will innovate in more goods. It is likely that innovation for some goods makes innovation for other goods easier. For example, as experience was obtained in the industrialization of some goods, it became easier to industrialize others. We now turn to modelling innovation externalities. Consider instead of (29) the innovation function,

$$
A_{t+\Delta t}=A_{j t}+\mu_{j} h\left(\xi_{j t}\right)\left(\left(\frac{\left.(1+\sigma) A_{1 t}-A_{j t}\right) \Delta t}{1+\sigma}\right)^{\beta}(v \Delta t)^{1-\beta}, \quad j \in\{1,2\},\right.
$$

in which we have eliminated the expression $S_{i t} / A_{1 t}$ using skills as absorptive capacity (compared to the leading technological edge due to the fishing out effect) and instead suppose that there are positive externalities $h\left(\xi_{j t}\right)$ in innovation related to the number of goods $\xi_{j t}$ being innovated for. We assume that $h(0)=0$ (so almost no research is possible if research is done for almost no goods), $h(1)=1$ (this sets the scale), and that $h$ is increasing in $\xi_{j t}$. We show that divergence in levels always happens between identical countries, so that a lagging country with the same parameters can never catch up without policies to compensate for the lack of externalities, and that divergence in growth rates is possible under certain conditions on $h$ at $\xi_{j t}=0$.

Proposition 7. Technological change in Countries 1 and 2 follows,

$$
\dot{A}_{j t}=\tilde{\mu}_{j} h\left(\xi_{j t}\right) \frac{(1+\sigma) A_{t t}-A_{j t}}{1+\sigma} \Upsilon\left(a_{t}\right)^{(1-\beta) / \beta}, \quad j \in\{1,2\} .
$$

Hence

$$
\frac{\dot{A}_{1 t}}{A_{1 t}}=\frac{\sigma}{1+\sigma} \tilde{\mu}_{1} h\left(\xi_{j t}\right) \Upsilon\left(a_{t}\right)^{(1-\beta) / \beta}, \quad \frac{\dot{A}_{2 t}}{A_{2 t}}=\tilde{\mu}_{2} h\left(\xi_{2 t}\right)\left(a_{t}^{-1}-\frac{1}{1+\sigma}\right)\left(a_{t}\right)^{(1-\beta) / \beta} .
$$


Hence the rate of growth of the relative technological level $a_{t}$ is:

$$
\frac{\dot{a}_{t}}{a_{t}}=\left(\tilde{\mu}_{2} h\left(\xi_{2 t}\right)\left(a_{t}^{-1}-\frac{1}{1+\sigma}\right)-\frac{\sigma}{1+\sigma} \tilde{\mu}_{1} h\left(\xi_{1 t}\right)\right) \Upsilon\left(a_{t}\right)^{\frac{1-\beta}{\beta}}
$$

Proof. Following the same profit maximization process we obtain (37) from (36) instead of (34) from (29). The remaining statements follow directly.

We study two cases. The first is when $a_{t}$ is near zero, to see if there can be divergence in growth rates. The second is for two identical economies, for which $a_{t}=1, \lambda=1$, and $\tilde{\mu}_{1}=\tilde{\mu}_{2}$. Here the question is whether the steady state $a_{t}=1$ is unstable, so that if Country 2 is lagging only slightly, it will permanently diverge, at least in levels. By considering identical economies, we simplify the mathematical considerations.

Lemma 8. The derivatives of $\xi_{1 t}$, $\xi_{2 t}$ with $b_{t}$, at $b_{t}=0$ are:

$$
\left.\frac{d \xi_{1 t}}{d b_{t}}\right|_{b_{t}=0}=-\frac{1}{1-\kappa},\left.\quad \frac{d \xi_{2 t}}{d b_{t}}\right|_{b_{t}=0}=\frac{1}{1-\kappa}
$$

In the case of identical economies, so $b_{t}=1$, where $\xi_{1 t}=\xi_{2 t}=\frac{1}{2}$,

$$
\left.\frac{d \xi_{1 t}}{d b_{t}}\right|_{b_{t}=1}=-\frac{1}{4}-\frac{\kappa}{8},\left.\quad \frac{d \xi_{2 t}}{d b_{t}}\right|_{b_{t}=1}=\frac{1}{4}-\frac{\kappa}{8}
$$

Proof. Differentiate (15), recalling $\frac{d \xi_{2 t}}{d b_{t}}=-\frac{d \xi_{1 t}}{d b_{t}}$, at $b_{t}=0$, where $\xi_{1 t}=1$ and $\xi_{2 t}=0$. The first result follows almost directly, obtaining $-\left.(1-\kappa) \frac{d \xi_{1 t}}{d b_{t}}\right|_{b_{t}=0}=1$ because there are so many zeros. For the second, recall at $b_{t}=1$, $\xi_{1 t}=\xi_{2 t}=\frac{1}{2}$. The derivative yields the quotient

$$
\frac{-\left.\frac{1}{2} \kappa \frac{d \xi_{1 t}}{d b_{t}}\right|_{b_{t}=1}-\left.\left(1-\frac{\kappa}{2}\right) \frac{d \xi_{1 t}}{d b_{t}}\right|_{b_{t}=1}-\left.\frac{d \xi_{1 t}}{d b_{t}}\right|_{b_{t}=1}\left(1-\frac{\kappa}{2}\right)-\left.\frac{1}{2} \kappa \frac{d \xi_{1 t}}{d b_{t}}\right|_{b_{t}=1}}{\frac{1}{2}\left(1-\frac{\kappa}{2}\right)}=1,
$$

from which the result follows.

We can now describe the technological dynamics in the case when in each country there are innovation externalities between goods. Figure 2 exemplifies Theorem 9.

Theorem 9. 1) Country 1 grows faster under trade than under autarchy if $h(1) Y_{t}>h\left(\xi_{1 t}\right) Y_{t}^{\text {autarchy }}$, that is, if innovation improves more from the gains of economic scale than it looses in innovation externalities as some of the innovation goes abroad.

2) Country 2, grow faster under autarchy than under free trade if $h(1) Y_{2 t}^{\text {autarchy }}>h\left(\xi_{2 t}\right) Y_{2 t}$, that is, if it gains more from innovation externalities when it closes than from the economies of scale under trade.

3) Countries identical in their innovation parameters and populations will diverge if they start from slightly different technological levels.

4) Divergence in growth rates is possible if innovation externalities grow sufficiently slowly for small economies, that is:

$$
h^{\prime}(0)<(1-\kappa) \frac{\sigma}{1+\sigma} \frac{\tilde{\mu}_{1}}{\tilde{\mu}_{2}} .
$$



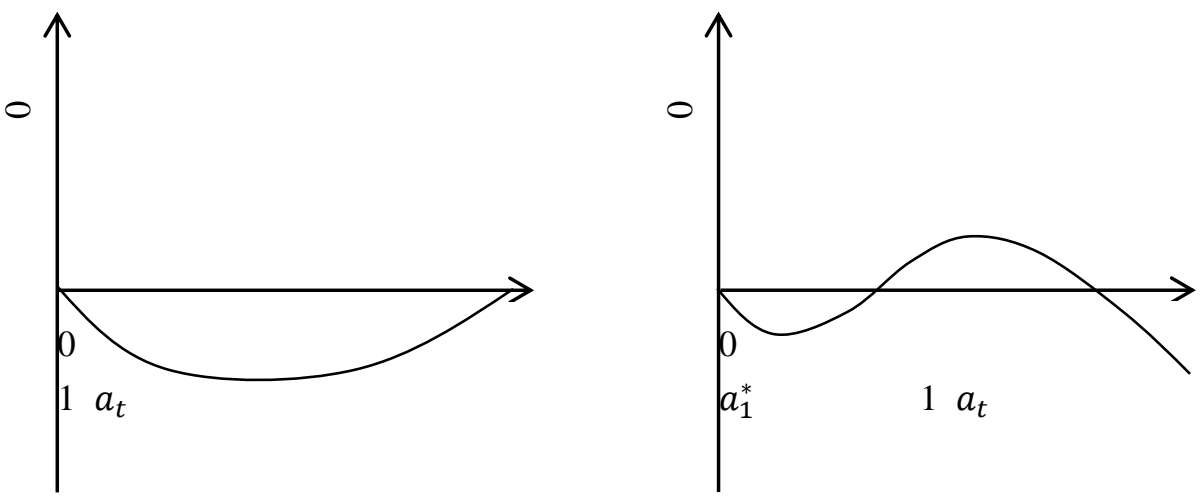

Figure 2. Two phase space diagram examples for relative technological change dynamics

Note. In the first example there is only divergence in growth rates. In the second there is also a steady state with divergence in levels. Additional configurations for the dynamics given by equation (39) are possible.

Proof. 1) By equation (38), $\dot{A}_{1 t} / A_{1 t}$ will be higher under trade than under autarchy if $h(1) \Upsilon\left(a_{t}\right)>h\left(\xi_{1 t}\right) \Upsilon(0)$, which is equivalent to the stated condition.

2) Equation (37) for the rate of technological change of Country 2 shows that by resorting to autarchy $h\left(\xi_{2 t}\right)$ will increase to $h(1)$. The convergence term $\left(a_{t}^{-1}-\frac{1}{1+\sigma}\right)$ will remain the same while the scale effect $\Upsilon\left(a_{t}\right)$ will be reduced. Thus if $h(1) Y_{2 t}^{\text {autarchy }}>h\left(\xi_{2 t}\right) Y_{2 t}$ growth will be faster under autarchy.

3) For identical economies

$$
H^{\prime}(1)=\tilde{\mu}_{1}\left[h^{\prime}\left(\frac{1}{2}\right)\left(1-\frac{1}{1+\sigma}\right)-h\left(\frac{1}{2}\right) \frac{1}{1+\sigma}-\frac{\sigma}{1+\sigma} h^{\prime}\left(\frac{1}{2}\right)-\frac{\sigma}{1+\sigma} h\left(\frac{1}{2}\right)\right]=-\tilde{\mu}_{1} h\left(\frac{1}{2}\right)<0,
$$

so if $a_{0}<1$ initially, $a_{t}$ cannot reach 1 . Hence Country 2 must diverge in levels or in growth rates.

4) Let $H\left(a_{t}\right)=\tilde{\mu}_{2} h\left(\xi_{2 t}\right)\left(1-\frac{a_{t}}{1+\sigma}\right)-\frac{\sigma}{1+\sigma} \tilde{\mu}_{1} h\left(\xi_{1 t}\right) a_{t}$, the function in the big bracket of (39) multiplied by $a_{t}$.

Since $h(0)=0, H$ satisfies $H(0)=0, H^{\prime}(0)=\tilde{\mu}_{2} h^{\prime}(0)-\tilde{\mu}_{1} \frac{\sigma}{1+\sigma}$, which is less than zero under the given condition. Hence $a_{t}=0$ is a stable steady state. Note therefore by L'Hopital's rule

$$
\lim _{a_{t} \rightarrow 0} \frac{\dot{a}_{t}}{a_{t}}=\tilde{\mu}_{2} \frac{h^{\prime}(0)}{1-\kappa} \Upsilon(0)^{(1-\beta) / \beta}-\frac{\sigma}{1+\sigma} \tilde{\mu}_{1} h\left(\xi_{1 t}\right)<0,
$$

so Country 2 diverges in growth rates.

Of course these results are stronger if countries initially have further disadvantages.

\section{Discussion}

Theorem 6 extends the results in Howitt and Mayer-Foulkes (2005) and shows that divergence in levels and in growth rates are possible under trade, as well as catching up and overtaking. The growth rate is found to be higher under trade than under autarchy because of a market scale effect that increases due to the assignment of production according to comparative advantages. Whether these scale effects exist or not has been subject to discussion, mainly because growth rates do not seem to be proportional to country size. However, the scale effect is really based on the scale of the sphere of influence of the technological leader.

Clark, O'Rourke, and Taylor (2014) find that while trade had only a small impact on British welfare in the 1760s, it had a very large impact in the 1850s. The cotton textiles sector became dependent on foreign markets for about $60 \%$ of its total sales. Thus trade not only allowed Britain to specialize in manufacture, the innovating sector, but also to produce for a much larger market, becoming the Workshop of the World. In turn, it depended on foreign markets, including its colonies, for both food and raw materials.

In the post 1960's context, most developed countries traded together and therefore shared the same scale effect namely the sum of their economies. It has been shown that the scale effect might be mitigated for example when 
$R \& D$ is expended in increasing the number of varieties. Thus there need not be a full linear scale effect as in these models. Nevertheless, a scale effect seems to have been present for the Industrial Revolution through world trade, focussing innovation in Great Britain; for the US catch-up to industrialization through the success of the American System by focussing innovation in the North; and for German catch-up to industrialization with the rize of railways in the mainland in Europe after 1840.

Britain's trade with its formal and informal empire, together with its advantage in manufacturing, focused innovation in Britain. An idea of the relative size of this effect is given by the following data, reflected in Figures 3 and 4. From 1820 to 1940 Britain's formal empire had a similar population to China, the largest country in the world with 381 million people in 1820. Each of the US, Russia, France, Germany and even the whole of Western Europe without the UK (which can be thought of potentially as an area of German influence) and the whole of the non-colonized world, was much smaller. In 1820 China's aggregate product was higher than the British Empire's. By 1870, the opposite held. An important point in comparing the forces of economic development in Britain and China is that there was no region in China where economic forces for innovation were as focused as they were in Britain, which functioned as the economic center of an economy as large as China's. This gives a strong reason why the Industrial Revolution occurred in Britain rather than China.

The high degree of economic competition associated with colonialism, high enough to have featured as a cause of the World Wars, is also evidence of an economic scale effect. Note how by 1913 Western European production (without the UK) had overtaken the production of the British Empire. There may be an underlying relationship between the income dominance shifts shown in Figure 4 and the World Wars.

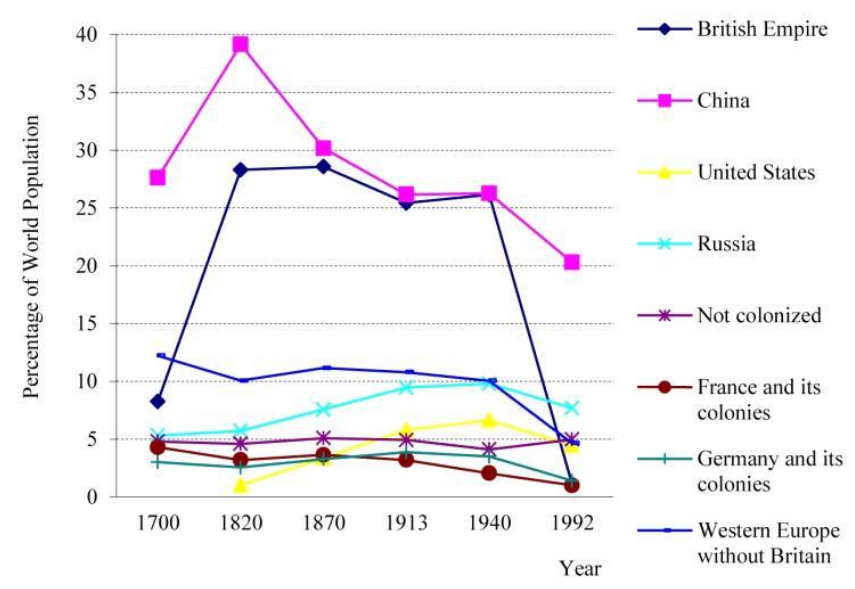

Figure 3. Population of various powers and regions

Note. Population shown as a proportion of world population, 1700-1992 (Maddison, 2001).

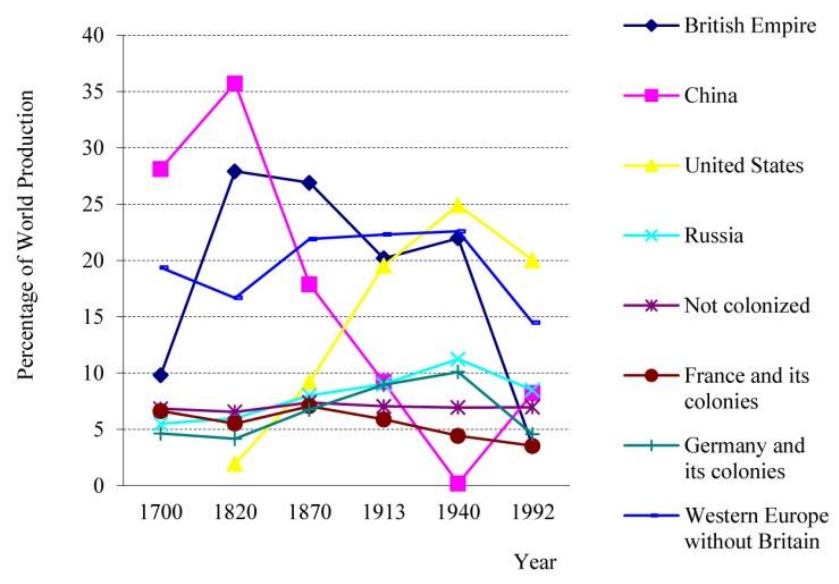

Figure 4. Production of various powers and regions

Note. Production shown as a proportion of world production, 1700-1992 (Maddison, 2001). 
Theorem 9 shows that innovation externalities can also lead to divergence in levels and in growth rates. Here innovation externalities between goods is the simplest general concept that relates innovation in some goods to innovation in other goods. In the case of $19^{\text {th }}$ Century Britain, we could also consider that its knowledge system had more knowledge on industrialization than other knowledge systems, and that therefore it was able to innovate with advantage in those goods most ammenable to industrialization. We could let the combination of functions on comparative advantage and $h$ represent these features to obtain the same results as in this Theorem.

Let us apply this theorem to the colonial diktat. Essentially the metropolis is Country 1 in the model, and its colonies together form Country 2. Even taking into account that the metropolis could trade with additional countries, at least from the point of view of each colony its trade situation looked like Country 2 in the model, since transport between colony and metropolis was conducted only on metropolis ships, and colonial exports could be made only to the metropolis. Production of manufactured goods that could compete with metropolitan products was banned, so that the set $\left[0, \xi_{l t}\right]$ of goods with high productivity and innovation externalities which Country 1 produced was protected. Moreover, since goods coming from other colonies had to pass through the metropolis (or at least be traded by it), for each colony these goods enlarged $\xi_{l t}$ or at least diminished market size in some goods from the set $\left(\xi_{2 t}, 1\right]$. The consequence was that Country 2 diverged, either in levels or in growth rates.

When the US obtained its independence from Britain and set up the American System, it opted to be closed and ceased to be Country 2 of this model. More generally, Theorem 9 explains the features shown in Table I. Brazil and Mexico, which were more closed to trade than China or India, diverged less. On the other hand, for various reasons including size and institutions, which feature in the model through the scale effect and the parameter $\mu_{j}$, Brazil and Mexico did not have the necessary conditions for catching up, as the US did.

Absorptive capacity and innovation externalities are specific, but quite general, causes that can simultaeously give rise to economic growth and divergence in the context of trade. There are others, for example agglomeration externalities as in Krugman (1991). These various different dynamics can of course combine in reality.

The model applies so long as Countries 1 and 2 each represent a knowledge system within which there is some common level of knowledge. If policy steps are taken to reduce knowledge boundaries between countries, then the forces for divergence are also reduced, since skill levels and externalities are shared.

It is worth commenting that so long as captive trade through a colonial system yielded economic advantages, convergence to development set up for advanced countries an economic pressure to compete in the colonial system. Thus convergence to development tended to also be convergence to colonial power, with an implicit military rivalry between advanced countries. Economic competition set up a dynamic of military rivalry that was an antecedent of the two World Wars. In the current scenario (2017) it may likewise be important to maintain a single rather than a fractured global economic system.

\section{Conclusions}

In the presence of comparative advantage, trade is of mutual benefit to comercial partners, which become more productive as they specialize in their sectors with comparative advantage. We are concerned here only with innovation that occurs in the same firms that carry out production. Therefore by allocating production, trade also allocates innovation sectors. Each comercial partner specializes in a number of sectors proportional to the size of its economy, which itself depends on its technological level. This implies that in the long-term trading partners' technological levels may diverge in levels or in growth rates. While this may depend simply on fixed innovation productivity differences between countries, it may also be an effect reinforced by differences in the number of sectors engaged in innovation in each country, and therefore by differences in their technological levels.

Technological change is a process in which innovators absorb leading technologies created by other innovators, so as to create new technologies for their own production sectors. These in turn produce spillovers and externalities for other sectors, which can to some extent be country specific.

We show that in the presence of trade between countries with different levels of development, this inherent structure of innovation can lead to the emergence of multiples steady states including divergence in levels or in growth rates.

The model is compatible with the emergence of development and underdevelopment in the long $19^{\text {th }}$ Century as a sequel of the Industrial Revolution, particularly in the context of the colonial diktat. It also explains different types of long-term divergence patterns observed for open and closed economies that remained underdeveloped in Latin America, Asia and Africa. It is also compatible with various subsequent episodes of catching up to 
development, such as Germany, the US and Japan.

The main policy conclusion is that trade must be sufficiently complemented with technology transfer. (Mayer Foulkes, 2015, shows that foreign direct investment does not necessarily achieve this transfer.)

\section{References}

Aghion, P., \& Howitt, P. (1992). A Model of Growth Through Creative Destruction. Econometrica: Journal of the Econometric Society, 323-351. https://doi.org/10.2307/2951599

Aghion, P., Howitt, P., \& Mayer-Foulkes, D. (2005). The Effect of Financial Development on Convergence: Theory and Evidence. The Quarterly Journal of Economics, 120(1), 173-222. https://doi.org/10.1162/0033553053327515

Aghion, P., Howitt, P., Brant-Collett, M., \& García-Peñalosa, C. (1998). Endogenous growth theory. MIT press.

Bairoch, P. (1997). Victoires et déboires. Paris: Gallimard.

Beaudreau, B. C. (2004). World Trade. iUniverse. Inc., New York.

Broadberry, S., \& Gupta, B. (2009). Lancashire, India, and shifting competitive advantage in cotton textiles, 1700-1850: the neglected role of factor prices1. The Economic History Review, 62(2), 279-305. https://doi.org/10.1111/j.1468-0289.2008.00438.x

Chapman, S. D. (1987). The cotton industry in the Industrial Revolution. In The Industrial Revolution A Compendium (pp. 1-64). Macmillan Education UK. https://doi.org/10.1007/978-1-349-10936-4_1

Clark, G., O'Rourke, K. H., \& Taylor, A. M. (2014). The growing dependence of Britain on trade during the Industrial Revolution. Scandinavian Economic History Review, 62(2), 109-136. https://doi.org/10.1080/03585522.2014.896285

Coe, D. T., \& Helpman, E. (1995). International R\&D spillovers. European Economic Review, 39(5), 859-887. https://doi.org/10.1016/0014-2921(94)00100-E

Everett, G., Hitchcock, S. H., Middleton, J., \& Timms, R. H. (2006). Samuel Slater - Hero or Traitor?: The Story of an American Millionaire's Youth and Apprenticeship in England. Milford: Maypole Promotions.

Howitt, P. (2000). Endogenous growth and cross-country income differences. American Economic Review, 829-846. https://doi.org/10.1257/aer.90.4.829

Howitt, P., \& Mayer-Foulkes, D. (2005). R\&D, Implementation, and Stagnation: A Schumpeterian Theory of Convergence Clubs. Journal of Money, Credit \& Banking (Ohio State University Press), 37(1). https://doi.org/10.1353/mcb.2005.0006

Maddison, A. (2004). World population, GDP and GDP per capita, 1-2000 AD. Retrieved from http://www.eco.rug.nl/ Maddison. This page has moved to: The Maddison-Project, 2013 version, http://www.ggdc.net/maddison/maddison-project/home.htm

Mayer-Foulkes, D. (2015). The challenge of market power under globalization. Review of Development Economics, 19(2), 244-264. https://doi.org/10.1111/rode.12140

Salisbury, W. A. (2015). The Civil War and the American System: America's Battle with Britain, 1860-1876. Executive Intelligence Review.

Spannaus, N., White, C., Hamilton, A., More, T., Henry, V. I. I. I., Gresham, T., ... \& Washington, G. (2015). The Political Economy of the American Revolution. Executive Intelligence Review.

Svedberg, P. (1978). The portfolio-direct composition of private foreign investment in 1914 revisited. The Economic Journal, 88(352), 763-777. https://doi.org/10.2307/2231977

Wilkins, M. (1970). The emergence of multinational enterprise: American business abroad from the colonial era to 1914 (Vol. 34). Cambridge, Mass: Harvard University Press.

\section{Copyrights}

Copyright for this article is retained by the author(s), with first publication rights granted to the journal.

This is an open-access article distributed under the terms and conditions of the Creative Commons Attribution license (http://creativecommons.org/licenses/by/4.0/). 